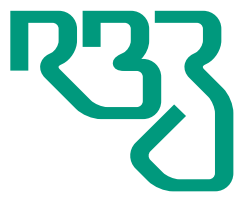

\section{Revista}

Brasileira de

Zootecnia

Brazilian Journal of Animal Science

ISSN 1806-9290

www.rbz.org.br

\title{
Biometric parameters of adult and growing Pêga donkeys
}

\author{
Camilla Garcia Moreira ${ }^{1}$ (iD), Madalena Lima Menezes ${ }^{1}$ (iD), Tamires Romão \\ Nunes $^{1}$ (iD), Thais Pagotti Mota ${ }^{1}$ (iD), Júlio Cesar de Carvalho Balieiro² ${ }^{2}$ iD, \\ Chiara Albano de Araujo Oliveira ${ }^{3}$ (iD), Roberta Ariboni Brandi ${ }^{*}$ (iD \\ ${ }^{1}$ Universidade de São Paulo, Faculdade de Zootecnia e Engenharia de Alimentos, \\ Departamento de Zootecnia, Pirassununga, SP, Brasil. \\ ${ }^{2}$ Universidade de São Paulo, Faculdade de Medicina Veterinária e Zootecnia, Departamento \\ de Nutrição e Produção Animal, Pirassununga, SP, Brasil. \\ ${ }^{3}$ Universidade Federal da Bahia, Escola de Medicina Veterinária e Zootecnia, Salvador, \\ BA, Brasil.
}

\begin{abstract}
This study aimed at establishing the morphological characteristics and morphometric indexes of Pêga donkeys, utilizing 47 animals, of which 22 were adults and 25 were growing donkeys. Prior to taking their measurements, the animals were restrained and made to stand squarely. The morphological data were measured, and the following morphometric indexes were determined: body index (BI), meloscopic index (MI), dactylothoracic index (DTI), weight in cannon index (WCI), conformation index (CFI), and real live weight (RLW). The experimental design was subdivided into plots and repeated in time, in which the animals represented the plot and the data collection times were the subplots. No sex effect was noted for the morphological measurements and morphometric indexes of growing donkeys. The effect of growth period was observed for all the variables. At birth, donkeys weighed around $14.86 \%$ of the weight of dams, and at six months they reached up to $40.37 \%$. For the height taken at the withers, the animals at birth were $67.77 \%$ of the height of dams, and at six months they achieved up to $84.45 \%$. Based on the morphometric indexes, it is suggested that adult and growing Pêga donkeys can be classified as being suited for both saddle and draft activities and possess a higher load capacity when compared with horses. A few indexes including BI, MI, and RLW need to be adjusted to be suitably used in rating the donkeys.
\end{abstract}

Keywords: equidae, growth, morphometry, morphology

\section{Introduction}

The Pêga donkeys are raised in Brazil to produce mules and animals for breeding, both having substantial economic worth in the country and with the well-recognized genetic potential for ambling gait (Oliveira, 2004).

To accurately evaluate the equid production, the development of animals must be observed (Santos et al., 2007), accompanied by morphometric evaluations (Hoffmann et al., 2013). Pimentel et al. (2011) stated that the morphometric evaluation of the animals is based on relationships between the development of various regions of the body, and that the animal is accepted as well-proportioned if the body parts are adapted to their designed functions. In the present evaluation, some of the indexes are investigated such as body index (BI), meloscopic index (MI), dactylothoracic index (DTI), weight in 
cannon index (WCI), conformation index (CFI), and real live weight (RLW) (Cabral et al., 2004; Brum, 2010; Pimentel et al., 2014).

There is a paucity of studies in the literature related to this field of knowledge, and more specifically for the Pêga donkeys. Brum (2010) investigated adult Pêga donkeys and suggested that these animals fall under the category of eumerics, having saddle characteristics.

Pimentel et al. (2014), in their study on adult Nordestino breed of donkeys, classified these animals as longilineal, which included animals of the racing type that possess a higher load capacity than horses. These authors also state that the indexes used were developed for horses, and this could be the reason for the differences between the results when applying them to donkeys.

This study was carried out to explore the morphological measurements and morphometric indexes of both adult and growing Pêga donkeys to define the morphometric parameters and aptitudes of this breed.

\section{Material and Methods}

This study received approval from the local Ethics Committee on Animal Use, case number: 2743200315. The experiment was conducted in Jaú, São Paulo, Brazil (latitude $22^{\circ} 17^{\prime} 44^{\prime \prime} \mathrm{S}$ and longitude $48^{\circ} 33^{\prime} 28^{\prime \prime}$ W) from January of 2015 to March 2016, using 22 female donkeys (jennies) in the age range of $12.73 \pm 4.78$ years and weighing $289.63 \pm 35.72 \mathrm{~kg}$, and their offspring, which were evaluated at six months of age ( 25 animals). Three of the adult female donkeys in the study had two pregnancies during the evaluation period, bringing the total to 47 animals.

The jennies were maintained in 1 ha per head of pasture land having Coast Cross grass (Cynodon dactylon (L) Pers) during the pregnancy period; ten days prior to giving birth, they were placed in masonry stalls and fed every day with $2 \mathrm{~kg}$ of natural matter of wet whole oats (Avena sp.) and $3 \mathrm{~kg}$ of natural matter of alfalfa hay (Medicago sativa) (Table 1).

The pasture samples of oats and alfalfa hay were stored in plastic bags, identified, and dried in a forced-circulation oven at $65^{\circ} \mathrm{C}$ for $72 \mathrm{~h}$. Dry matter, crude protein, mineral matter, neutral detergent fiber, acid detergent fiber, cellulose, hemicellulose, and lignin were determined by adopting the methodology of Silva and Queiroz (2002). Gross energy was determined using a calorimetric pump.

Thirty days post foaling, the animals with their offspring were relocated back to the pasture.

The jennies were weighed on a 1000-kg capacity digital electronic scale (Leader B-650 ${ }^{\circledR}$ ) every month until they reached six months of age; their body condition score (BCS) was measured using the methodology described by Pearson and Oussat (1996). The growing donkeys were weighed every month from birth to six months, employing the identical scale used for the adult animals.

For reliability, the morphological measurements were always recorded by the same person and always from the left side of the animal (Melo et al., 2011). To accomplish this, animals were restrained and

Table 1 - Nutritional composition of the ingredients used in the feed of Pêga jennies during the first month of lactation

\begin{tabular}{lccc}
\hline Component $\left(\mathrm{g} \mathrm{kg}^{-1}\right)$ & Coast Cross grass & Whole oat & Alfalfa hay \\
\hline Dry matter & 339.7 & 877.3 & 822.1 \\
Mineral matter & 75.1 & 36.2 & 85.7 \\
Crude protein & 69.4 & 158.6 & 221.4 \\
Neutral detergent fiber & 793.2 & 375.9 & 476.3 \\
Acid detergent fiber & 351.5 & 172.1 & 330.8 \\
Cellulose & 301.8 & 137.6 & 249.3 \\
Hemicellulose & 441.7 & 203.8 & 145.5 \\
Lignin & 49.7 & 34.5 & 81.5 \\
Gross energy $\left(\mathrm{kcal} \mathrm{kg}^{-1}\right)$ & 3800 & 3900 & 4700 \\
\hline
\end{tabular}


made to stand squarely on a masonry surface without a slope (Cabral et al., 2004). The adult animals were restrained using halters, while the growing ones were restrained by the person positioning his or her hands on the chest and croup and/or using the halter. The morphological parameters thus recorded are listed in Table 2 (Brum, 2010; Pimentel et al., 2011; Godoi et al., 2012; Pimentel et al., 2014).

After evaluating the morphological measurements, the morphometric indexes were calculated as cited below and described earlier (Cabral et al., 2004; Brum, 2010; Pimentel et al., 2014; Melo et al., 2011; Godoi et al., 2012).

Body index (BI): This relates to the body length with the thoracic perimeter and enables the classification of the animals as longilineal ( $\mathrm{BI} \geq 90)$, mediolineal $(86 \leq \mathrm{BC} \leq 88)$ and brevilineal $(\mathrm{BI} \leq 85)$.

$$
B I=\frac{\text { body length }}{\text { thoracic perimeter }} \times 100
$$

Meloscopic index (MI): This refers to the height of the forelimb with the three circumferences thereof (forearm, knee, and cannon), categorized as longilineal ( $\mathrm{MI}>1$ ), mediolineal (MI = 1), and brevilineal $(\mathrm{MI}<1)$, respectively.

$$
M I=\frac{\text { elbow }- \text { ground distance }}{\text { forearm }+ \text { knee }+ \text { cannon perimeter }}
$$

Dactylothoracic index (DTI): This is indicative of the relationship between the mass of the animal and the members that support it and facilitates the classification of the animals as hypermetric (heavy DTI > 11.5), eumetric (medium - $10.5 \leq$ DTI $\leq 10.8$ ), or hypometric (light - DTI < 10.5).

$$
D T I=\frac{\text { cannon perimeter }}{\text { thoracic perimeter }} \times 100
$$

\begin{tabular}{|c|c|}
\hline $\begin{array}{l}\text { Morphological } \\
\text { measurement }\end{array}$ & Description \\
\hline Scale weight & Using electronic scale with $1000 \mathrm{~kg}$ capacity \\
\hline Withers and croup height & Through hipometer applied to the highest point of these regions \\
\hline Body length & $\begin{array}{l}\text { Measured with tape placed between the cranial portions of the greater tubercle of the humerus and } \\
\text { caudal of the ischial tuberosity }\end{array}$ \\
\hline Thoracic perimeter & Measured with tape placed just behind the withers, behind shoulders, and passing by the girth \\
\hline $\begin{array}{l}\text { Forearm, cannon, and } \\
\text { knee perimeter }\end{array}$ & Measured with the tape placed around in the center of these regions \\
\hline Shoulder length & $\begin{array}{l}\text { Distance of the dorsal edge of scapular cartilage and distal angle of the scapula or the central portion } \\
\text { of the scapular-humeral joint }\end{array}$ \\
\hline Back-loin length & Distance of the ends of the spinous process of T8 and T9 and cranial portion of sacral tuberosity \\
\hline Croup lenght & Distance of the cranial portion of the iliac tuberosity and caudal portion of the ischial tuberosity \\
\hline Head width & Measured between the free portion of the right supra-orbital edge and the left edge \\
\hline Chest width & Distance of the side edges of the left and right scapular-humeral joints \\
\hline Hip width & Distance of the side portions of the iliac tuberosity \\
\hline Forearm length & Distance of the central area of the humeral-radial joint to the lateral middle third of the carpal joint \\
\hline
\end{tabular}

Table 2 - Description of morphological measurements of jennies and growing Pêga donkeys 
Weight in cannon index (WCI): This indicates the capacity of the members to shift the body weight.

$$
W C I=\frac{\text { cannon perimeter }}{\text { body weight }} \times 100
$$

Real live weight (RLW): This is an estimation of the live weight of the animal, calculated by using the thoracic perimeter (TP) cubed multiplied by 80 .

$$
R L W=T P^{3} \times 80
$$

Conformation index (CFI): This index enables the evaluation of the aptitude of the animal, identifying it as saddle $(\mathrm{CFI}=2.11)$, racing $(\mathrm{CFI}<2.11)$, or draft type $(\mathrm{CFI}>2.11)$.

$$
C F I=\frac{\text { thoracic perimeter }^{2}}{\text { withers height }}
$$

A mixed model for repeated measurements was adopted for the analyses, according to the work of Littell et al. (1998). The statistical model was as follows:

$$
\mathrm{y}_{\mathrm{ijk}}=\mu+\alpha_{\mathrm{i}}+\mathrm{a}_{\mathrm{ij}}+\mathrm{t}_{\mathrm{k}}+(\alpha \mathrm{t})_{\mathrm{ik}}+\varepsilon_{\mathrm{ijk}}
$$

in which $y_{\mathrm{ijk}}$ is the response to the evaluation $\mathrm{k}$ of the individual $\mathrm{j}$ in the sex $\mathrm{i} ; \mu$ is the overall mean; $\alpha_{i}$ is the fixed effect of sex $i$; $a_{i j}$ is the random effect of animal $j$ on sex $i$; $t_{k}$ is the fixed effect of time $k$; $(\alpha t)_{i k}$ is the effect of a double interaction of sex with time; and $\varepsilon_{\mathrm{ijk}}$ is the random error. The fixed effect $\alpha_{i}$ was considered a factor of variation between the animals, and the repeated measurements within the animal were accepted as the evaluation conditions reflecting the correlation structure within animals. As the main effects for sex $\left(\alpha_{\mathrm{i}}\right)$ and sex $\times$ time $(\alpha \mathrm{t})_{\mathrm{ik}}$ were not significant $(\mathrm{P}>0.05)$, they were deleted from the model, retaining the remaining effects, both fixed and random. In this model, the $\mathrm{a}_{\mathrm{ij}}$ effect was considered independent and showing a variance of $\sigma 2 \mathrm{a}$. Different covariance structures were evaluated and selected using model cooperation, based on the AIC proposed by Akaike (1974). All analyses were performed using the PROC MIXED procedure of the SAS program (Statistical Analysis System, version 9.4).

\section{Results}

In the first month of lactation, the jennies weighed $289.63 \pm 35.72 \mathrm{~kg}$, values close to those cited by the Associação Brasileira dos Criadores de Jumento Pêga (ABCJPÊGA) as the ideal for females. The BCS was 4.68, ranking the animals with a less than moderate score.

The morphometric measurements of jennies during lactation and/or gestation were taken to determine the reference values to monitor their offspring, because these data are not available in the literature (Table 3). The values recorded were similar to that observed for the male Pêga donkeys (Brum, 2010).

The growth of young donkeys was monitored through a comparative study with the measurements of the dam. No studies were found in the literature comparing the evaluations for growing donkeys in terms of the dams; however, it is accepted that the morphological measurements of the jennies may have affected the results observed.

The birth weight of young donkeys, taken on an electronic scale, was $43.05 \pm 8.39 \mathrm{~kg}$, representing roughly $14.86 \%$ of the weight of the dams and, at six months, they reached $116.91 \pm 4.47 \mathrm{~kg}$, equivalent to around $40.37 \%$ of the weight of dams (Table 4).

The effect of growth period $(\mathrm{P}<0.001)$ was noted for all variables under investigation (Table 5). The sex of the animal exerted no effect $(\mathrm{P}>0.001)$ for any of the variables.

From the morphometric indexes of jennies, the BI was $95.7 \pm 4.61$ (Table 6), enabling them to be categorized as longilineal, this classification being suitable for animals adapted to the racing activity, which is different from the goals of producing the Pêga donkeys.

R. Bras. Zootec., 48:e20180297, 2019 
The DTI was $10.9 \pm 0.44$ (Table 6 ), falling between the eumetric $(10.5 \leq$ DTI $\leq 10.8)$ and hypermetric (DTI > 11.5) ratings, suggesting that the donkeys in this study are adapted for saddle activity, as well as for draft work.

The CFI was $1.66 \pm 0.13$ (Table 6), facilitating the categorization of adult donkeys as longilineal and adapted to saddle activities, as indicated by the DTI.

The WCI of adult female donkeys was $5.7 \pm 0.65$ (Table 6), implying that the Pêga donkeys have traction capacity superior to that of some horse breeds.

For the MI of adult donkeys, an average value of $1.1 \pm 0.08$ (Table 6 ) indicated that the Pêga donkeys could be adapted to racing activities, showing a result similar to that presented by the BI determination.

The RLW of adult female donkeys was $257.9 \pm 28.06 \mathrm{~kg}$ (Table 6), which was lower than the actual weight obtained on the electronic scale $(289.62 \mathrm{~kg})$.

For growing animals, the time of evaluation $(\mathrm{P}<0.001)$ affected the values of the morphometric indexes (Table 7).

Table 3 - Morphological measurements (cm), mean \pm SD, of Pêga jennies

\begin{tabular}{lccccc}
\hline Morphological measurement & $\mathrm{N}$ & Mean & Minimum & Maximum & CV (\%) \\
\hline Withers height & 22 & $131.1 \pm 5.5$ & 121.0 & 149.0 & 4.2 \\
Croup height & 22 & $136.1 \pm 7.6$ & 129.0 & 167.0 & 5.6 \\
Thoracic perimeter & 22 & $147.5 \pm 5.3$ & 137.0 & 160.0 & 3.6 \\
Forearm perimeter & 22 & $29.2 \pm 2.3$ & 24.0 & 32.0 & 7.5 \\
Knee perimeter & 22 & $26.8 \pm 1.1$ & 25.0 & 29.0 & 4.1 \\
Cannon perimeter & 22 & $16.1 \pm 0.8$ & 15.0 & 18.0 & 4.7 \\
Croup lenght & 22 & $43.1 \pm 2.4$ & 39.0 & 48.0 & 5.5 \\
Forearm length & 22 & $35.5 \pm 3.8$ & 31.0 & 46.0 & 10.7 \\
Cannon lenght & 22 & $17.2 \pm 2.1$ & 15.0 & 22.0 & 12.1 \\
Body length & 22 & $141.0 \pm 5.4$ & 131.0 & 151.0 & 3.8 \\
Back-loin length & 22 & $62.6 \pm 6.7$ & 54.0 & 79.0 & 10.7 \\
Neck length & 22 & $52.5 \pm 2.8$ & 48.0 & 58.0 & 5.3 \\
Head length & 22 & $55.7 \pm 3.0$ & 48.0 & 61.0 & 5.4 \\
Shoulder length & 22 & $42.7 \pm 2.6$ & 37.0 & 50.0 & 5.9 \\
Head width & 22 & $26.5 \pm 2.4$ & 23.0 & 31.0 & 9.2 \\
Hip width & 22 & $46.1 \pm 3.7$ & 42.0 & 56.0 & 7.9 \\
Chest width & 22 & $31.6 \pm 3.1$ & 26.0 & 40.0 & 9.7 \\
Elbow-ground distance & 22 & $76.5 \pm 4.2$ & 70.0 & 84.0 & 5.5 \\
\hline N & & & & \\
\hline
\end{tabular}

$\mathrm{N}$ - number of animals; CV- coefficient of variation.

Table 4 - Weight (electronic scale), mean $\pm S D$, of growing Pêga donkeys and proportion to the weight of dams $(289.63 \pm 35.72 \mathrm{~kg})$

\begin{tabular}{lcc}
\hline Age (months) & Weight $(\mathrm{kg})$ & \% related to the weight of the dam \\
\hline 0 (close to birth) & $43.05 \pm 8.39$ & 14.86 \\
1 & $56.07 \pm 4.82$ & 19.35 \\
2 & $72.41 \pm 4.25$ & 25.00 \\
3 & $87.71 \pm 4.21$ & 30.28 \\
4 & $102.76 \pm 4.43$ & 35.48 \\
5 & $112.10 \pm 4.35$ & 38.71 \\
6 & $116.91 \pm 4.47$ & 40.37 \\
\hline
\end{tabular}


Table 5 - Morphological measurements (cm), mean \pm SD, of growing Pêga donkeys

\begin{tabular}{|c|c|c|c|c|c|c|c|c|}
\hline \multirow{2}{*}{$\begin{array}{l}\text { Morphological } \\
\text { measurement }\end{array}$} & \multicolumn{7}{|c|}{ Age (months) } & \multirow{2}{*}{$\mathrm{P}$} \\
\hline & 0 & 1 & 2 & 3 & 4 & 5 & 6 & \\
\hline Withers height & $88.8 \pm 1.4$ & $92.2 \pm 0.8$ & $97.9 \pm 0.8$ & $101.5 \pm 0.8$ & $105.8 \pm 0.9$ & $109.4 \pm 0.9$ & $110.7 \pm 0.9$ & $<0.0001$ \\
\hline Croup height & $91.4 \pm 1.5$ & $95.5 \pm 0.9$ & $101.7 \pm 0.9$ & $105.6 \pm 0.9$ & $109.8 \pm 0.9$ & $113.7 \pm 0.9$ & $114.7 \pm 0.9$ & $<0.0001$ \\
\hline Thoracic perimeter & $75.5 \pm 2.1$ & $81.8 \pm 1.2$ & $90.4 \pm 1.2$ & $98.1 \pm 1.2$ & $102.6 \pm 1.3$ & $106.3 \pm 1.3$ & $108.4 \pm 1.4$ & $<0.0001$ \\
\hline Forearm perimeter & $17.7 \pm 0.6$ & $19.2 \pm 0.3$ & $20.8 \pm 0.3$ & $21.6 \pm 0.3$ & $22.3 \pm 0.4$ & $22.7 \pm 0.4$ & $23.3 \pm 0.4$ & $<0.0001$ \\
\hline Knee perimeter & $20.7 \pm 0.4$ & $21.3 \pm 0.3$ & $22.9 \pm 0.3$ & $23.4 \pm 0.3$ & $24.1 \pm 0.3$ & $24.5 \pm 0.3$ & $24.7 \pm 0.3$ & $<0.0001$ \\
\hline Cannon perimeter & $10.8 \pm 0.3$ & $11.6 \pm 0.2$ & $12.6 \pm 0.2$ & $13.4 \pm 0.2$ & $13.8 \pm 0.2$ & $14.1 \pm 0.2$ & $14.1 \pm 0.2$ & $<0.0001$ \\
\hline Croup lenght & $23.3 \pm 0.8$ & $26.4 \pm 0.5$ & $29.6 \pm 0.4$ & $31.8 \pm 0.5$ & $33.2 \pm 0.5$ & $33.9 \pm 0.5$ & $35.1 \pm 0.5$ & $<0.0001$ \\
\hline Forearm length & $26.0 \pm 0.9$ & $26.6 \pm 0.5$ & $27.9 \pm 0.5$ & $28.9 \pm 0.5$ & $29.7 \pm 0.6$ & $30.8 \pm 0.6$ & $31.1 \pm 0.6$ & $<0.0001$ \\
\hline Cannon lenght & $10.8 \pm 0.5$ & $15.3 \pm 0.3$ & $15.8 \pm 0.3$ & $16.2 \pm 0.3$ & $16.8 \pm 0.3$ & $16.8 \pm 0.3$ & $17.4 \pm 0.3$ & $<0.0001$ \\
\hline Body length & $67.8 \pm 2.1$ & $77.3 \pm 1.2$ & $86.8 \pm 1.1$ & $94.5 \pm 1.2$ & $99.2 \pm 1.3$ & $103.4 \pm 1.3$ & $104.4 \pm 1.3$ & $<0.0001$ \\
\hline Back-loin length & $27.4 \pm 1.4$ & $32.7 \pm 0.7$ & $37.5 \pm 0.7$ & $40.7 \pm 0.7$ & $43.2 \pm 0.8$ & $45.6 \pm 0.8$ & $48.3 \pm 0.8$ & $<0.0001$ \\
\hline Neck length & $28.1 \pm 1.3$ & $31.2 \pm 0.7$ & $35.9 \pm 0.6$ & $38.3 \pm 0.7$ & $39.8 \pm 0.7$ & $41.8 \pm 0.7$ & $42.9 \pm 0.8$ & $<0.0001$ \\
\hline Head length & $32.9 \pm 1.1$ & $35.1 \pm 0.6$ & $38.6 \pm 0.6$ & $41.1 \pm 0.6$ & $43.5 \pm 0.7$ & $45.5 \pm 0.7$ & $46.3 \pm 0.7$ & $<0.0001$ \\
\hline Shoulder length & $24.4 \pm 0.7$ & $26.1 \pm 0.4$ & $29.0 \pm 0.4$ & $30.1 \pm 0.4$ & $31.7 \pm 0.4$ & $32.6 \pm 0.4$ & $33.1 \pm 0.4$ & $<0.0001$ \\
\hline Head width & $17.8 \pm 0.6$ & $18.7 \pm 0.3$ & $20.4 \pm 0.3$ & $20.9 \pm 0.3$ & $21.0 \pm 0.3$ & $21.4 \pm 0.3$ & $21.9 \pm 0.3$ & $<0.0001$ \\
\hline Hip width & $22.0 \pm 1.1$ & $24.7 \pm 0.6$ & $27.5 \pm 0.6$ & $29.3 \pm 0.6$ & $30.3 \pm 0.6$ & $32.6 \pm 0.6$ & $32.7 \pm 0.7$ & $<0.0001$ \\
\hline Chest width & $18.6 \pm 0.8$ & $20.7 \pm 0.5$ & $22.7 \pm 0.4$ & $24.3 \pm 0.5$ & $24.9 \pm 0.5$ & $25.5 \pm 0.5$ & $25.9 \pm 0.5$ & $<0.0001$ \\
\hline $\begin{array}{l}\text { Elbow-ground } \\
\text { distance }\end{array}$ & $60.1 \pm 1.0$ & $62.1 \pm 0.6$ & $65.2 \pm 0.6$ & $67.7 \pm 0.6$ & $69.4 \pm 0.6$ & $71.1 \pm 0.6$ & $72.2 \pm 0.7$ & $<0.0001$ \\
\hline
\end{tabular}

Table 6 - Morphometric indexes, mean \pm SD, of adult Pêga donkeys

\begin{tabular}{lccccc}
\hline Morphometric index & $\mathrm{N}$ & Mean & Minimum & Maximum & CV (\%) \\
\hline Body index & 22 & $95.7 \pm 4.61$ & 86.75 & 102.19 & 4.82 \\
Meloscopic index & 22 & $1.1 \pm 0.08$ & 0.95 & 1.26 & 7.50 \\
Dactyl-thoracic index & 22 & $10.9 \pm 0.44$ & 10.00 & 11.74 & 4.05 \\
Weight in cannon index & 22 & $5.7 \pm 0.65$ & 4.63 & 6.84 & 11.40 \\
Conformation index & 22 & $1.66 \pm 0.13$ & 1.26 & 1.94 & 0.79 \\
Real live weight & 22 & $257.9 \pm 28.06$ & 206.00 & 328.00 & 10.88 \\
\hline
\end{tabular}

$\mathrm{N}$ - number of animals; CV- coefficient of variation.

Table 7 - Morphometric indexes, mean \pm SD, of growing Pêga donkeys (from birth to six months of age)

\begin{tabular}{lcccccc}
\hline \multirow{2}{*}{ Age (months) } & \multicolumn{7}{c}{ Morphometric indexes } \\
\cline { 2 - 7 } 0 (close to birth) & $90.84 \pm 1.8$ & $1.22 \pm 0.023$ & $14.30 \pm 0.3$ & $28.9 \pm 1.41$ & $0.64 \pm 0.036$ & $32.03 \pm 4.4$ \\
1 & $95.15 \pm 1.0$ & $1.19 \pm 0.013$ & $14.22 \pm 0.1$ & $25.3 \pm 0.79$ & $0.73 \pm 0.019$ & $43.76 \pm 2.8$ \\
2 & $96.19 \pm 0.9$ & $1.16 \pm 0.012$ & $13.88 \pm 0.1$ & $19.7 \pm 0.67$ & $0.84 \pm 0.019$ & $60.42 \pm 2.7$ \\
3 & $96.36 \pm 1.1$ & $1.16 \pm 0.013$ & $13.62 \pm 0.2$ & $17.1 \pm 0.66$ & $0.95 \pm 0.019$ & $75.34 \pm 2.8$ \\
4 & $96.87 \pm 1.1$ & $1.15 \pm 0.014$ & $13.52 \pm 0.2$ & $15.2 \pm 0.71$ & $0.99 \pm 0.021$ & $87.54 \pm 2.9$ \\
5 & $97.23 \pm 1.1$ & $1.16 \pm 0.014$ & $13.32 \pm 0.2$ & $14.1 \pm 0.69$ & $1.04 \pm 0.021$ & $97.60 \pm 2.9$ \\
6 & $96.82 \pm 1.1$ & $1.17 \pm 0.015$ & $13.12 \pm 0.2$ & $13.0 \pm 0.71$ & $1.06 \pm 0.022$ & $105.47 \pm 2.9$ \\
P-value & $<0.001$ & $<0.001$ & $<0.001$ & $<0.001$ & $<0.001$ & $<0.001$ \\
Mean & $95.97 \pm 4.34$ & $1.2 \pm 0.061$ & $13.68 \pm 0.8$ & $17.4 \pm 5.04$ & $0.92 \pm 0.157$ & $74.18 \pm 25.24$ \\
\hline
\end{tabular}

BI - body index; MI - meloscopic index; DTI - dactyl-thoracic index; WCI - weight in cannon index; CFI - conformation index; RLW - real live weight. 
The BI of the growing donkeys (Table 7) was above 90, enabling the animals to be classified as longilineal from birth to six months of age, categorizing these animals as the racing type, similar to the observation made for adult Pêga donkeys (Table 6).

From the values of the DTI, the growing animals were classified as hypermetric (DTI > 11.5) from birth to six months (Table 7), and the WCI ranged from $28.9 \pm 1.41$ to $13.0 \pm 0.71$.

The CFI of growing Pêga donkeys ranged from $0.64 \pm 0.036$ to $1.06 \pm 0.022$ from birth to six months (Table 7), classifying them as having a saddle aptitude, similar to the observation made for adult female donkeys (Table 6).

The MI of growing donkeys showed an average of $1.2 \pm 0.061$ (Table 7), similar to that reported for adult donkeys (Table 6). This classification indicated that growing and adult Pêga donkeys could be adapted for racing activities.

The RLW revealed a variation from $32.03 \pm 4.4$ to $105.47 \pm 2.9 \mathrm{~kg}$ from birth to weaning (Table 7), with lower values noted from the scale (Table 4 ).

\section{Discussion}

The scores recorded from the body condition of Pêga jennies in the first month of lactation concurred with those reported by Pearson and Ouassat (1996) and Yoseph et al. (2005). Although the BCS presented was less than moderate, the average weight observed for the jennies was close to values cited by the ABCJPÊGA (2016) as being ideal for females.

The BCS affects the reproductive efficiency in mares (Gastal et al., 2004) and, according to the NRC (2007), mares with BCS values of 5 (moderate), on a scale of 1 to 9 , can possess maximum reproductive efficiency. No data were found in the literature on BCS of female donkeys, either during pregnancy or lactation; however, the findings from this study bear close similarity to those cited by the NRC (2007) as being ideal for the higher reproductive efficiency in mares.

The morphological measurements of female Pêga donkeys investigated in this study (Table 3) were higher than those reported for the Nordestino breed (Pimentel et al., 2014; Mariz et al., 2014) and bore similarity to those observed for the male Pêga donkeys (Brum, 2010) and were close to those described for the Catalan, one of the forming breeds of the Pêga (Folch and Jordana, 1997).

For adult donkeys, withers height $(\mathrm{WH})$ was $131.1 \pm 5.5 \mathrm{~cm}$ (Table 3 ), falling well within the range established by the ABCJPÊGA (2016), which require a minimum WH of $120 \mathrm{~cm}$ for females. The findings of this study corroborate those of Brum (2010), who reported a mean value of $131 \mathrm{~cm}$ for male Pêga donkeys, but differ from those reported by Mariz et al. (2014) and Pimentel et al. (2014), who investigated the Nordestino breed of donkeys and reported WH values of $117 \mathrm{~cm}$ and $106 \mathrm{~cm}$, respectively, indicating that Pêga donkeys are taller. These data also corroborate the findings of Oliveira (2004), who reported that the Pêga animals are larger when compared with other national breeds.

The average croup height $(\mathrm{CH})$ in this study was $136.1 \pm 7.6 \mathrm{~cm}$ (Table 3), higher than the $133 \mathrm{~cm}$ reported by Brum (2010), in his evaluation of the Pêga breed, and close to the value of $135.79 \mathrm{~cm}$ reported by Folch and Jordana (1997) in their study of the Catalan breed.

The $5 \mathrm{~cm}$ variation observed between the heights of both withers and croup (Table 3) was because the $\mathrm{CH}$ was higher than the $\mathrm{WH}$. This variation is the maximum accepted value for the registration of animals by the ABCJPÊGA (2016). According to Nascimento (1999), it is ideal when the CH is equal to or greater than that of $\mathrm{WH}$, because when the $\mathrm{CH}$ is less than the $\mathrm{WH}$, the center of gravity of the animal moves cranially, thus affecting the quality of the movement (Brum, 2010; Nascimento, 1999).

The WH is also related to body length (BL). Based on the work of Oom and Ferreira (1987), well-proportioned animals should be as tall as they are long, implying that the ratio of WH to BL should be equal to 1 . In the jennies studied, this ratio was 0.93 indicating that the donkeys are longer than they are tall, which is considered a desirable trait for draft animals (Torres and Jardim, 1981), one of 
the main uses of the donkeys and their crosses. Folch and Jordana (1997) stated that donkeys, besides being capable of saddle activity, have higher draft capacity when compared with horses.

On assessing the thoracic perimeter (TP) of adult female donkeys, the observed value of $147.5 \pm 5.3 \mathrm{~cm}$ (Table 3) exceeded the recommended limit of $144 \mathrm{~cm}$ for adult females and $148 \mathrm{~cm}$ for adult males by the ABCJPÊGA (2016). This higher value can be explained by the fact that most of the animals in this study were in the stages of lactation and pregnancy, concurring with the statement cited by Kost'uková et al. (2015), meaning that TP is a morphological measurement that shows great variation and can be affected by physiological and health conditions. The TP value obtained in this study fell below the one observed by Brum (2010) for the Pêga male donkeys and above the value cited by Pimentel et al. (2014) for the Nordestino donkeys. Pêga animals are better adapted to handle physical efforts when compared with the Nordestino animals, because, according to Nascimento (1999) and Pimentel et al. (2011), animals possessing superior chest amplitude (larger thoracic volume) can withstand a greater degree of physical effort.

For cannon perimeter (CP) of adult female donkeys, the mean value obtained was $17.2 \pm 2.1 \mathrm{~cm}$ (Table 3), similar to results reported by Brum (2010), but higher than that reported by Pimentel et al. (2014). In their work on draft equids, Mariz et al. (2014) reported CP for horses, mules, and donkeys (Nordestino breed) as $17.5,15.8$, and $13.5 \mathrm{~cm}$, respectively, and stated that the horses had a higher traction capacity than did the mules and donkeys evaluated. The CP value for donkeys employed in this study $(17.2 \mathrm{~cm})$ was similar to that observed by Mariz et al. (2014) for draft horses, which may suggest that the Pêga donkeys investigated have a weight carrying capacity similar to that of horses adapted to traction, but higher than that of mules and Nordestino donkeys.

To follow the growth of young donkeys, a comparative study was performed utilizing the measurements of the dam, as reported earlier for horses by Julliand and Martin-Rosset (2005). The growth rate of the animals in this study bears close similarity to growth rate of horses, as they achieved $25 \%$ of the adult body weight at two months of age and $40 \%$ of the adult body weight at six months (Table 4), as stated by Julliand and Martin-Rosset (2005).

No effect was exerted by sex $(\mathrm{P}>0.001)$ on morphological measurements of growing donkeys until they reached six months of age, corroborating the results of Folch and Jordana (1997) in their study on the Spanish breed of Catalan donkeys and those of Pimentel et al. (2014) in their work on the Nordestino breed.

The WH in the growing donkeys ranged from $88.8 \pm 1.4$ to $110.7 \pm 0.9 \mathrm{~cm}$ from birth to six months (Table 5), which at birth, represents approximately $67.77 \%$ of the height of the dam, and around $84.45 \%$ at weaning (six months), almost the same as the report cited by Julliand and Martin-Rosset (2005), who stated that equine foals are born having approximately $60 \%$ of the adult height and achieving around $80 \%$ at six months. According to Rezende et al. (2000), the horses considered best adapted to saddle activity will reach about $90 \%$ of the adult height at six months, data which is almost the same as the findings observed in this study.

In growing animals, $\mathrm{WH}$ is also related to $\mathrm{CH}$, and the same is true for adult animals. The donkeys were born possessing around $67.14 \%$ of the $\mathrm{CH}$ of dams $(91.40 \pm 1.5 \mathrm{~cm})$ (Table 5) and, at six months, they reached nearly $83.52 \%$ of this height $(113.7 \pm 0.99 \mathrm{~cm})$. As for the adult donkeys, in growing animals, variations below $5 \mathrm{~cm}$ were observed during the six months of evaluation (Table 5); this assessment during the development of the donkeys is significant for the prior selection of animals to register them in the breeders' association.

In the assessment of the TP, values of $75.5 \pm 2.1$ at birth and $108.4 \pm 1.4 \mathrm{~cm}$ at six months were recorded (Table 5). The TP plus the BL of growing animals were the morphological measurements that showed higher variations during the assessment months (Table 5), thus demonstrating higher growth dynamics than any other body measurement (Mota et al., 2010), which may suggest a similar growth behavior in these two variables. The BL ranged from $67.8 \pm 2.1 \mathrm{~cm}$ at birth to $104.4 \pm 1.3 \mathrm{~cm}$ at six months (Table 5).

R. Bras. Zootec., 48:e20180297, 2019 
A proportional relationship is evident between $\mathrm{BL}$ and $\mathrm{WH}$, in which the $\mathrm{BL}$ of donkeys at birth is $76.35 \%$ of the $\mathrm{WH}$, whereas for the adult female donkeys, it is $107.55 \%$ of the $\mathrm{WH}$. This corroborates the results recorded by Willoughby (1975), who observed that BL of the American Quarter horse breed is 76 to $76.2 \%$ of the $\mathrm{WH}$ at birth, while for the adults, it is 106.7 to $107.6 \%$, which may indicate that both the Pêga donkeys investigated in this study and some equine breeds are born higher than longer; when they reach adulthood, this ratio becomes equal or gets reversed, and the animals become slightly longer than high (Cabral et al., 2004; Brum, 2010; Oom and Ferreira, 1987), as observed with the adult female donkeys assessed in this study.

On estimating the $\mathrm{CP}$ of growing donkeys, a variation of $10.8 \pm 0.3$ to $14.1 \pm 0.2 \mathrm{~cm}$ was noted from birth to six months (Table 5), and these values represent, at birth, about $67.06 \%$ of the CP of dams and, at six months, approximately $88.88 \%$. The CP evaluation is crucial, because it is related to the ability to shift weight, and a higher CP may indicate superior traction capacity (Cabral et al., 2004; Mariz et al., 2014), as observed in the adult female donkeys studied here (Table 3). It is also essential for evaluating a few of the morphometric indexes such as MI, DTI, and WCI, as discussed below (Cabral et al., 2004; Brum, 2010).

In the analysis of morphometric indexes of adult female donkeys (Table 6), at the first evaluation of BI, it was confirmed that the animals could be classified as longilineal, similar to the observations recorded in other studies conducted on donkeys (Brum, 2010; Pimentel et al., 2014; Mariz et al., 2014; Folch and Jordana, 1997). Longilineal animals are morpho-functionally adapted to the racing activity, indicating the longer BL in relation to the thoracic depth, which thus provides greater speed (Cabral et al., 2004; McManus et al., 2010). This classification of donkeys differs from the saddle-type animals, which is one of the objectives of Pêga donkeys for the production of ambling-gaited mules (ABCJPÊGA, 2016). The morphometric indexes used were developed for horses (Pimentel et al., 2014), and a few differences may arise when applying these indexes for donkeys.

On assessing DTI, the adult female donkeys showed a distinction between the eumetric and hypermetric types (Table 6); this could indicate that the donkeys investigated are adapted for saddle activity as well as for use as draft animals, fulfilling both the objectives of raising donkeys in Brazil (Brum, 2010; ABCJPÊGA, 2016). The results observed in this study agree with other research conducted by testing donkeys, such as the work of Mariz et al. (2014), who studied the Nordestino donkeys used for draft and reported a rating between the eumetric and hypermetric types. Folch and Jordana (1997), while studying the Catalan donkey breed, and Pimentel et al. (2014), using the Nordestino breed, classified the animals as hypermetric, whereas Brum (2010), using the Pêga breed, classified the animals as eumetric. Only a minimum variation was noted between the studies using donkeys, probably because this index can be a reliable indicator for the use of these animals and, for donkeys, which can do both saddle and draft activities, as cited above.

Weight in cannon index (Table 6) fell below that observed in the Nordestino donkeys by Pimentel et al. (2014), but was higher than that reported for the Mangalarga Marchador horses by Cabral et al. (2004), indicating that Pêga donkeys have a lower traction capacity than do the Nordestino breed and are superior for this feature, compared with the Mangalarga horses. When relating the WCI to the DTI, the Pêga donkeys were observed to be adapted both to the saddle and draft activities, but showed greater efficiency in saddle activity (Brum, 2010). Based on the DTI, they did not exhibit as high a traction capacity as do the Nordestino donkeys, and their characteristic feature was their ambling gait, a highly sought-after trait by breeders and which gets transmitted genetically to their offspring (Oliveira, 2004; ABCJPÊGA, 2016).

The capacity for saddle activity is once again confirmed when evaluating the CFI (Table 6), in which the donkeys were classified as longilineal, implying that they possessed an aptitude to be saddled (Pimentel et al., 2014). This result corroborates the findings of Mariz et al. (2014), who stated that in the adult Nordestino donkeys, the value of the CFI was below 2, which also enabled classifying these animals as longilineal, and demonstrating that, although they are used as draft animals, they possess the conformation for saddle activities (Oliveira, 2004). 
On assessing the MI for adult donkeys, it was noted that they were classified as longilineal, indicating that these animals possessed long members and were adapted to activities involving speed. Regarding the corporal index, the MI may not have been appropriate to classify the donkeys in this study, because it had been developed only for horses, and therefore more studies which have applied this index to the species are necessary.

Considering the RLW of the Pêga jennies, it was evident that the mean value observed was below the actual weight obtained on the electronic scale $(289.62 \mathrm{~kg})$, indicating the necessity to adapt this index to weight prediction for the adult donkeys.

On analyzing the morphometric indexes of the growing donkeys (Table 7), the BI results facilitated classifying them as longilineal from birth to six months of age. Cabral et al. (2004) reported different findings in their study on growing horses and classified the animals at three months of age as brevilineal and, after four months, when the animals exhibited a BI value higher than 85 , they were reclassified as mediolineal. This classification observed for the growing animals (Table 7) confirms the results observed for the adult donkeys (Table 6), distinguishing them as the racing type, a classification very remote from fulfilling the objective of producing Pêga donkeys (Brum, 2010; ABCJPÊGA, 2016).

The results of the DTI of the growing donkeys were similar to those observed by Cabral et al. (2004) in their work using the growing Mangalarga Marchador breed of horses, indicating that donkeys are born heavier and possess the characteristics of draft animals, and this classification may get altered in adulthood, as cited above for the adult donkeys (Table 6).

On analyzing the WCI in the growing donkeys, similar results to those observed by Cabral et al. (2004) were confirmed. This index indicates the ability of the members to move the body mass, and the decrease in this index as age advances can be explained by the weight gained by the animal (Table 4), with only a slight variation in the cannon perimeter (Table 5). The WCI in the growing donkeys was higher than that observed in the growing Mangalarga Marchador breed of horses (Cabral et al., 2004), likely because the donkeys have a superior ability to move the body mass, which is indicative of a greater capacity for traction, compared with horses as cited earlier by Folch and Jordana (1997) in their study on the Catalan donkeys. This superior traction capacity of donkeys is confirmed when the relationship between the BL and WH is observed, as mentioned above.

As observed in the adult donkeys, the morphometric indexes classify the growing donkeys as being adapted to both traction and saddle activities, very similar to the CFI of the growing animals, ranging from $0.64 \pm 0.036$ to $1.06 \pm 0.022$ from birth to six months (Table 7), which were classified as longilineal, or animals possessing saddle aptitude (Pimentel et al., 2014).

On assessing the MI, as well as the $\mathrm{BI}$, it can be confirmed that these animals are adapted to the racing activity, as they have been classified as longilineal from birth to six months of age (Table 7), and the animals possess long limbs, the characteristic feature of racing animals, according to Cabral et al. (2004), who ranked the Mangalarga Marchador horses as being longilineal from birth to adulthood.

On assessing the RLW of the growing donkeys, a variation of $32.03 \pm 4.4$ to $105.47 \pm 2.9 \mathrm{~kg}$ was observed from birth to weaning (Table 7), while the weight on the scale ranged from $43.05 \pm 8.39$ to $116.91 \pm 4.47 \mathrm{~kg}$ (Table 4). Therefore, for the growing animals, RLW also requires adjustments for greater efficiency in predicting the actual weight.

\section{Conclusions}

Donkeys are born weighing approximately $14.86 \%$ of the weight and $67.77 \%$ of the height of dams, and, at six months, they reach up to around $40.37 \%$ of that weight and $84.45 \%$ of that height. They are morphologically adapted both to saddle as well as to draft activities and possess a higher load capacity when compared with horses.

A few morphometric indexes, such as body index, conformation index, meloscopic index, and real live weight index need adjustments to be accurately used in rating donkeys.

R. Bras. Zootec., 48:e20180297, 2019 
The morphometric study of donkeys from birth is significant in monitoring the adequate growth rates for the species and evaluating growth disorders caused by diseases or poor nutrition. Thus, utilizing the dam as a reference for the growth parameters facilitates monitoring the donkey development.

\section{Conflict of Interest}

The authors declare no conflict of interest.

\section{Author Contributions}

Conceptualization: R.A. Brandi. Funding acquisition: R.A. Brandi. Investigation: C.G. Moreira and R.A. Brandi. Methodology: C.G. Moreira, M.L. Menezes, J.C.C. Balieiro and R.A. Brandi. Project administration: C.G. Moreira, M.L. Menezes, T.R. Nunes, T.P. Mota and R.A. Brandi. Resources: C.G. Moreira and R.A. Brandi. Software: J.C.C. Balieiro. Supervision: C.G. Moreira and R.A. Brandi. Validation: R.A. Brandi. Visualization: C.G. Moreira, J.C.C. Balieiro and R.A. Brandi. Writing-original draft: C.G. Moreira and R.A. Brandi. Writing-review \& editing: C.G. Moreira, C.A.A. Oliveira and R.A. Brandi.

\section{References}

Akaike, H. 1974. A new look at the statistical model identification. IEEE Transactions on Automatic Control 19:716-723. https://doi.org/10.1109/TAC.1974.1100705

ABCJPÊGA - Associação Brasileira de Criadores de Jumentos Pêga. 2016. Padrão da raça. Available at: <http://www. jumentopegabrasil.com.br>. Accessed on: Apr. 28, 2016.

Brum, P. P. 2010. Avaliação morfométrica de asininos machos da raça Pêga: medidas lineares e determinação das proporções corporais. Dissertação de monografia. Pontifícia Universidade Católica de Minas Gerais, Betim.

Cabral, G. C.; Almeida, F. Q.; Quirino, C. R.; Azevedo, P. C. N.; Pinto, L. F. B. and Santos, E. M. 2004. Avaliação morfométrica de equinos da raça Mangalarga Marchador: Índices de conformação e proporções corporais. Revista Brasileira de Zootecnia 33:1798-1805. https://doi.org/10.1590/S1516-35982004000700018

Folch, P. and Jordana, J. 1997. Characterization, reference ranges and the influence of gender on morphological parameters of the endangered Catalonian donkey breed. Journal of Equine Veterinary Science 17:102-111. https://doi.org/10.1016/ S0737-0806(97)80347-4

Gastal, M. O.; Gastal, E. L.; Spinelli, V. and Ginther, O. J. 2004. Relationships between body condition and follicle development in mares. Animal Reproduction Science 1:115-121.

Godoi, F. N.; Bergmann, J. A. G.; Almeida, F. Q.; Santos, D. C. C.; Miranda, A. L. S.; Vasconcelos, F. O.; Oliveira J. E. G.; Kaipper, R. R. and Andrade, A. M. 2012. Morfologia de potros da raça Brasileiro de Hipismo. Ciência Rural 43:736-742. https://doi.org/10.1590/S0103-84782013005000023

Hoffmann, G.; Bentke, A.; Rose-Meierhöfer, S.; Ammon, C.; Mazetti, P. and Hardarson, G. H. 2013. Estimation of the body weight of Icelandic horses. Journal of Equine Veterinary Science 33:893-895. https://doi.org/10.1016/j. jevs.2013.01.002

Julliand, V. and Martin-Rosset, W. 2005. The growing horse: nutrition and prevention of growth disorders. Wageningen Academic Publishers, Wageningen, The Netherlands. EAAP publication No. 114. p.15-21.

Kost'uková, M.; Černohorska, H.; Bihuncova, I.; Oravcova, I.; Sobotkova, E. and Jiskrova, I. 2015. Characteristics of morphological parameters of donkeys in the Czech Republic. Acta Universitatis Agricultura e Silvicultura e Mendeliana e Brunensis 63:419-424. https://doi.org/10.11118/actaun201563020419

Littell, R. C.; Henry, P. R. and Ammerman, C. B. 1998. Statistical analysis of repeated measures data using SAS procedures. Journal of Animal Science 76:1216-1231. https://doi.org/10.2527/1998.7641216x

Mariz, T. M. A.; Escodro, P. B.; Dittrich, J. R.; Souza Neto, M.; Lima, C. B. and Ribeiro, J. S. 2014. Padrão biométrico, medidas de atrelagem e índice de carga de equídeos de tração urbana do município de Arapiraca, Alagoas. Archives of Veterinary Science 19:01-08. https://doi.org/10.5380/avs.v19i2.34085

McManus, C.; Paiva, S.; Louvandini, H.; Melo, C. and Seixas, L. 2010. Jumentos no Brasil. INCT: Informação GenéticoSanitária da Pecuária Brasileira. (Série Técnica: Genética).

Melo, J. B.; Pires, D. A. F.; Ribeiro, M. N.; Santos, D. O. and Silva, H. G. O. 2011. Estudo zoométrico de remanescentes da raça equina nordestina no município de Floresta, Pernambuco - Brasil. Actas Iberoamericanas de Conservación Animal 1:71-74.

R. Bras. Zootec., 48:e20180297, 2019 
Mota, M. D. S.; Oliveira, N. and Puoli Filho, J. N. P. 2010. Avaliação do crescimento em potros da raça Quarto de Milha. Revista electrónica de Veterinária 11(1).

Nascimento, J. F. 1999. Mangalarga Marchador: Tratado Morfofuncional. Associação Brasileira dos Criadores do Cavalo Mangalarga Marchador, Belo Horizonte. 577p.

NRC - National Research Council. 2007. Nutrients requirements of horses. National Academy of Sciences, Washington, DC. 341p.

Oliveira, V. B. 2004. Uma visão técnica e pedagógica sobre os muares. Dissertação (M.Sc.). Universidade Federal Rural do Rio de Janeiro, Rio de Janeiro.

Oom, M. M. and Ferreira, J. C. 1987. Estudo biométrico do cavalo Alter. Revista Portuguesa de Ciências Veterinárias 83:101-148.

Pearson, R. A. and Oussat, M. 1996. Estimation of the liveweight and body condition of working donkeys in Morocco. Veterinary Record 138:229-233. https://doi.org/10.1136/vr.138.10.229

Pimentel, M. M. L.; Câmara, F. V.; Dantas, R. A.; Freitas, Y. B. N.; Dias, R. V. C. and Souza, M. V. 2011. Biometria de equinos de vaquejada no Rio Grande do Norte, Brasil. Acta Veterinaria Brasilica 5:376-379.

Pimentel, M. M. L.; Pinheiro, M.; Maia Filho, H.; Sakamoto, S. M.; Nobre, F. V. and Dias, R. V. C. 2014. Parâmetros biométricos de asininos (Equus asinus) utilizados em provas de corrida no estado do Rio Grande do Norte. Acta Veterinaria Brasilica 8:136-143.

Rezende, A. S. C.; Sampaio, I. B. M.; Legorreta, G. L. and Moreira, D. C. A. 2000. Efeito de dois diferentes programas nutricionais sobre o desenvolvimento corporal de potros Mangalarga Marchador. Revista Brasileira de Zootecnia 29:495-501. https://doi.org/10.1590/S1516-35982000000200024

Santos, A. S.; Souza, G. S.; Abreu, U. G. P.; McManus, C. and Comastri Filho, J. A. 2007. Monitoramento do desenvolvimento de cavalos pantaneiros por meio de curvas de crescimento. Archivos de Zootecnia 56(Sup. 1):647-654.

Silva, D. J. and Queiroz, A. C. 2002. Análise de alimentos: Métodos químicos e biológicos. 3. ed. UFV, Viçosa, MG. 235p.

Torres, A. P. and Jardim, W. R. 1981. Criação do cavalo e de outros equinos. Livraria Nobel, São Paulo.

Willoughby, D. P. 1975. Growth and nutrition in the horse. A.S. Barnes, Cranbury.

Yoseph, S.; Smith, D. G.; Mengistu, A.; Teklu, F.; Firew, T. and Betere, Y. 2005. Seasonal variation in the parasite burden and body condition of working donkeys in East Shewa and West Shewa regions of Ethiopia. Tropical Animal Health and Production 37(suppl. 1):35-45. https://doi.org/10.1007/s11250-005-9004-3 